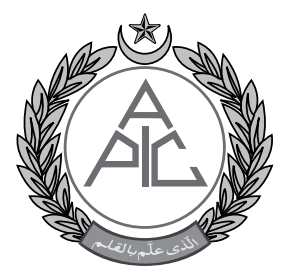

\title{
Main considerations in the design of an intensive care unit
}

\author{
Saira Mehboob ${ }^{1}$, Ahmed Mujadid Burki²
}

${ }^{1}$ Graded Anesthesiologist, Combined Military Hospital, Okara-56300 (Pakistan) ${ }^{2}$ Classified Anesthesiologist and Intensivist, Combined Military Hospital, Rawalpindi-46000 (Pakistan)

Correspondence:

Col Ahmed Mujadid Burki, Classified Anesthesiologist and Intensivist, Combined Military Hospital, Rawalpindi-46000 (Pakistan);

Phone: +92 300509 7882

E-mail: ahmedburki2004@

yahoo.com

\begin{abstract}
The objective of my study was to review the latest recommendations for the infrastructure; human resources; intensive care unit (ICU) design and setting; monitoring and management medical equipment and facilities. Designing an ICU requires both clinical expertise of the critical care practitioner; knowledge of architecture and regulatory and safety standard as well as determination of the level of care to be provided at the hospital. The modern ICU consists of a reception area, patient care area, clinical support and storage area. It should be adequately lit with flexibility of equipment maneuverability for management of patient during emergencies. While setting up a new intensive care unit, clinicians should abreast themselves with the latest recommendation and guidelines for ICU design.
\end{abstract}

Key words: Intensive Care Units; Design, Facility; Health Care Facilities; Manpower; Evidence-Based Facility Design; Hemodynamic Monitoring

Citation: Mehboob S, Burki AM. Main considerations in the design of an intensive care unit. Anaesth Pain \& Intensive Care 2018;22 Suppl 1:S13-S16

Received: 18 Sep 2018

Reviewed: 20 Oct 2018

Accepted: 5 Nov 2018

\section{INTRODUCTION}

Critical care medicine is increasingly being recognised as pivotal to improve patient outcomes. In the developing countries, like Pakistan, despite limited resources and scant skilled human resources, intensive care units (ICUs) under the supervision of critical care specialists are making major inroads. Specialist training - Fellowship by College of Physicians \& Surgeons Pakistan (FCPS), in critical care medicine was started in 2009. It has been a step forward in availability of trained staff for ICUs. An effective ICU requires architectural, structural, as well as optimal functionality of the set up. Studies have shown that an efficient ICU design has direct effect on patient morbidity and mortality; helps reduce medicine errors, reduces length of ICU stay, improves patient outcome as well as reduces the treatment cost. ${ }^{1,2}$

\section{THREE LEVELS OF ADULT IC}

There are three levels of adult critical care. The level
1 are patients who require monitoring/ intervention, clinical input after their discharge from higher level of care. The level 2 patients require pre-operative optimization or extended postoperative care, usually receiving single organ support or basic respiratory support. The level 3 patients require advanced respiratory support or minimum of 2 organ supports. ${ }^{3}$ Guidelines are published by various intensive care societies with the purpose to help the clinician and administrator for the construction, renovation and designing of an effective ICU under optimal conditions. These guidelines by ACCM, NHS, FGI are regularly updated and are designed for healthcare institutions. ${ }^{4}$ Critical care units are designed according to the patient care requirement; admission and discharge criteria; expected rate and duration of bed occupancy; human resource available and availability of equipment. The optimal management of a critically ill patient requires efficient and safe use of human resource as well as equipment and medication. The ICU staff must be able to effectively 
use specialized equipment in emergency situations. The objective of this paper is to review the latest recommendations for the infrastructure; human resources; ICU design and setting; monitoring and management medical equipment and facilities.

ICU Design Formulation: It is a multidisciplinary effort. Designing an ICU requires both clinical expertise of the critical care practitioner; knowledge of architecture and regulatory and safety standards as well as determination of the level of care to be provided at the hospital. The team includes a coordinator, intensivist / anesthetist; administrator, finance representative, clinical microbiologist, architect / biomedical engineer, manufacturer / supplier of equipment and furniture. ${ }^{5}$ The Society of Critical Care Medicine offers recommendations for ICU design and staffing. Depending on specific requirements, a tertiary care level ICU may range from 4 to 50 beds, with subdivision into specialist areas, e.g. neurosurgical, cardiothoracic, adult medical or surgical ICU or pediatric intensive care.

ICU Design: The following considerations are recommended for an efficiently working ICU:

1. Site: An ICU is an independent subunit of the hospital. It should have an easy access to emergency department, radiology suite, laboratory, blood bank facility and operating rooms. No trespassing should be allowed. The reception and counselling room for the attendants should be comfortable and practical. ${ }^{4}$

2. Entry / exit point: There should be a single entry/ exit point to ICU for the patients. A separate entry should be dedicated for the supplies and staff; emergency exit in case of disaster or emergency. Entrance should have video camera monitoring and telephone or intercom for communication between staff and visitors. The entrance and exit should be adequately sized to allow rapid movement of patients, beds, equipment and personnel in and out in case of emergency. Sliding glass doors with break-away capability are recommended over standard doors. The doorway should be at least one meter wide. ${ }^{6}$

3. Size: The recommended size of the ICU is 1-4 beds per 100 hospital beds. It is recommended to divide a larger ICU into pods of 8-15 beds for better patient care. ${ }^{7}$

4. Floor Layout: The total area of the ICU should be 2.5-3 times the patient care area. For simplicity and functionality, it can be divided into following parts: a. Reception area: A receptionist should be placed at the entrance. Waiting area for visitors can be planned at reception with 1-2 seats for every ICU beds. Counselling room should be separate from the waiting area and can be planned at the reception. ${ }^{4}$

b. Patient care area: The recommended area for each patient depends on basic design. An open ICU requires $125-150 \mathrm{sq} \mathrm{ft}$ for each bed; whereas, $150-180 \mathrm{sq} \mathrm{ft}$ is required for the single room setup; with adequate access to the head of each bed. ${ }^{8,9}$ All patients should have adequate lighting and preferable visual access to the outdoor. The ICU should have adequate natural light through windows. ${ }^{10}$ The window covering should be in accordance with the infection control guidelines. All the patients should be under direct or indirect visual supervision of trained staff at all times. The alarms from patients monitors and patients call systems should be audible to staff at all times. To avoid unnecessary noise pollution, sound absorbing and antiseptic material should be used for the flooring, walls as well as ceiling. Each bed should have adequate number of service outlets. These can be provided as articulating arm, columns or horizontal method. The articulating arm or boom configuration provides maximum maneuverability and allows better patient access during emergencies. ${ }^{11}$ The number of gas, electric and suction requirements depends on the individual ICU set up. However, it is reasonable to state that each service outlet should have at least two oxygen and suction ports; one air supply and scavenging system porta with 5-15 electric outlets. They should be accessible from both sides of the patient. ${ }^{12}$ At least $50 \%$ of electric outlets should be connected to hospital emergency power system. Each patient should have a specially designed bed; separate bins to collect dirty linen, contaminated and hazardous waste and sharps. ${ }^{13}$ Provision of chairs would depend upon the type and requirement of individual ICU. The temperature and light control of the patient area should be decided by the intensivist in-charge. A high intensity light source should be readily available. It can be portable, or wall or ceiling mounted. The general lighting should preferably be adjustable and indirect to avoid visual glare to the patient. ${ }^{14}$ Individual hand hygiene facility should be available for each bed. Alcohol gel dispensers with effective disinfectants should be placed in a location of convenience, easy accessibility and have a visual reminder for hand hygiene. 
Sinks should be placed near entrance and near waste disposal area. Liquid soap dispensers are preferred over soap bars. Disposable paper towels dispenser and dustbin should be in close proximity to sink to avoid spillage of water onto floor. Hands free sinks are preferred over foot or hand operated sinks. ${ }^{15-18}$

c. Clinical support Zone: It includes all the facilities related to diagnosis and management of critically ill patient. Laboratory, radiology suites and operating rooms may be in close proximity to the ICU, whereas renal replacement therapy, bronchoscopy or endoscopy suites may be provided as parts of ICU. ICU should have access to 24 hour clinical laboratory services. Point of care bedside testing equipment may be provided for ABGs, basic chemistry and electrolyte analysis. Portable radiological imaging facilities must be accessible to ICU including ultrasound machines

d. Unit support zone: this should include designated equipment storage area, staff facilities, seminar room, nursing and doctors' offices, administrative area and cleaner's area.

e. The environment: the floor should be uncluttered and organized for optimal working especially during emergency situations. No loose wiring or tubing should be present that can get in the way of patient care. The humidity of $30-60 \%$ and room temperature $70-75^{\circ} \mathrm{F}$ should be controlled as per infection control recommendations.

5. The assisted shower room: One shower room (8 $\left.\mathrm{m}^{2}\right)$ and a toilet $\left(4.5 \mathrm{~m}^{2}\right)$ should be designed per 6-8 beds which should have room for wheel chair / stretcher movement. ${ }^{5}$

6. The Equipment. The type and quantity of the equipment depends upon the type, size and requirement of individual ICU. There should be a regular system in place for maintenance, repair and replacement and safety checks of the equipment.

a. Monitoring equipment: This includes the standard monitoring with ECG, heart rate, NIBP, temperature, respiratory rate as well as invasive monitoring like IBP, CVP, urine output, BSR and $\mathrm{EtCO}_{2}$, ETT cuff pressure monitoring.

b. Basic equipment: This includes ventilators for invasive and non-invasive ventilation; hand ventilation assemblies; equipment for airway access, vascular access, defibrillation and pacing, chest drainage; infusion and specialized pumps; portable transport equipment; specialized bed; access to ultrasound for intravascular access or E-FAST scan.

c. Specialized equipment: for diagnostic or therapeutic procedure like RRT, IABP, echocardiography (transthoracic or transesophageal), ECMO etc. should be available as per individual ICU requirement. ${ }^{19}$

\section{Staffing requirement: ${ }^{4}$}

a. Every level 3 ICU should be under the care of a specialist intensivist. Level 1 and level 2 ICU can be under the supervision of a doctor with clinical practice predominantly in the intensive care medicine. At least one specialist must exclusively be in-charge of ICU. During working hours, this specialist must be predominantly present in the ICU and must be accessible to junior doctors or staff at all times. Daily rounds must be conducted at least twice a day.

b. In addition, at least one registered medical practitioner (MO or PGR) with appropriate level of experience and expertise must be present in ICU at all times. The MO should not be in charge of more than 8-15 patients at any time.

c. A nurse in charge of the unit must have a post registration qualification/ experience in critical care nursing. She must be over and above the nursing staff directly looking after the patients. A minimum of 1:1 nursing for ventilated and critically ill patients and 1:2 for less acutely ill patients must be maintained. Nursing staff ratio of greater than 1:1 may be required in complex situations (ECMO, CRRT). At least $50 \%$ of nursing staff must be experienced/ qualified in critical care nursing. The nursing staff running the educational activities and managing administrative jobs at a tertiary care hospital should be supernumerary to clinical nurses.

d. Support staff be employed as required e.g. respiratory therapist, nutritionist, physiotherapist, computer technician, biomedical engineer, social worker, psychiatrist, microbiologist, pharmacist, cleaners, clerical staff.

\section{CONCLUSION}

The optimal intensive care design can help improve patient care and reduce morbidity and mortality. It requires multidisciplinary approach with state of the art architecture, clinical expertise and availability of appropriate equipment. The intensivist and 
physician setting up newer ICU setup must keep themselves abreast with the latest recommendations and guidelines for intensive care development
Conflict of interest: Nil declared by the author

Authors' contribution: Both authors took part in the preparation of this manuscript.

\section{REFERENCES}

1. Harvey MA. Critical care unit bedside design and furnishing: Impact on nosocomial infections. Infect Control Hosp Epidemiol 1998;19:597-601 [PubMed]

2. Leaf DE, Homel P, Factor PH. Relationship between ICU Design and mortality. Chest. 2010;137(5):1022-7 [PubMed]

3. Intensive Care Society Standards@2009-Levels of Critical Care for Adult patients.ICS 2009

4. 20.0 Intensive Care Unit. Indian Health Facility Guidelines. Part B. Draft 1.2; July 2014. Available at http://healthfacilityguidelines. com/Guidelines/ViewPDF/HFGIndia/part_B intensive_care_unit (Accessed at 10 September 2018)

5. Guidelines for Intensive Care Unit Design. Faculty of Critical Care Medicine. College of Anaesthesiologist \& Intensivist of Sri Lanka. 2016. Available at; https://criticalcare.Ik/ wp-content/uploads/2015/06/ICUDESIGN-GUIDELINE-final.pdf

6. Rungta N, Govil D, Nainan S, Munjal M,,Divatia J, Jani CK. Intensive care planning and designing in India, Guidelines 2010. Guideline Committee ISCCM. [Free full text]

7. Stoddard JC. Design, staffing and equipment requirements for an intensive care unit. Int Anesthesiol
Clin. 1981;19:77-95. [PubMed]

8. The Facility Guidelines Institute: Guidelines for Design and Construction of Health Care Facilities. Chicago, IL, The Facility Guidelines Institute, 2010.

9. Cadenhead C. Square footage allocation in ICUs. Pheonix, AZ, 35 Critical care Conference.2005

10. Ulrich RS, Zimring C, Barch XZ, DuBose J, Seo HB, Choi YS, et al. A review of the research literature on eveidnec based healthcare design. HERD.2008;1-61-125 [PubMed]

11. Pati D, Evans J, Waggner L, Harvey T. An exploratory examination of medical gas boom versus traditional headwalls in intensive care unit design. Crit Care Nurs Q.2008;31340-356 [PubMed] DOI: 10.1097/01. CNQ.0000336820.12171.cf

12. Compressed Gas Association: Guide for Medical gas supply system at customer sites. M-1. Chantily VA. Compressed Gas Association.2003, p 68

13. Thompson DR, Hamilton DK, Cadenhead CD, Swoboda SM, Schwindel SM, Anderson DC, et al. Guidelines for intensive care unit design. Crit Care Med 2012;40:15861600 [PubMed]

14. Jaiswal SJ, Garcia S, Owens RL. Sound and Light Levels Are Similarly Disruptive in ICU and non-ICU Wards.
J Hosp Med. 2017 Oct;12(10):798804. [PubMed] doi: 10.12788/ jhm.2826.

15. Zaragoza M, Sallés $M$, Gomez J, Bayas JM, Trilla A. Handwashing with soap or alcoholic solutions? A randomized clinical trial of its effectiveness. Am J Infect Control. 1999;27:258-61 [PubMed] DOl: 10.1053/ic.1999.v27.a97622

16. Public Health Ontario: Best Practices for Hand Hygiene in all Health Care Settings, $4^{\text {th }}$ Edition, April 2014. Available at https:// www.publichealthontario.ca/en/ eRepository/2010-12\%20BP\%20 Hand\%20Hygiene.pdf (Accessed on 16 September 2018)

17. Kaplan LM, McGuckin M. Increasing handwashing compliance with more accessible sinks. Infect Control.1986;7:408-410 [PubMed]

18. Larson E, McGeer A, Quraishi ZA, Krenzischek D, Parsons BJ, Holdford $J$, et al. Effect of an automated sink on handwashing practices and attitudes in high-risk units. Infect Control Hosp Epidemiol.1991;12:422-8 [PubMed]

19. Minimum standard for intensive care units. College of Intensive Care Medicine of Australia and new Zealand.IC-1.2011 ABN:18-134282 103. (Available online) 